\title{
Development of automatic healthcare instruction system via movement gesture sensor for paralysis patient
}

\author{
S. A. C. Aziz, A. F. Kadmin, N. Rahim, W. H. W. Hassan, I. F. A. Aziz, M. S. Hamid, R. A. Hamzah \\ Centre for Telecommunication Research \& Innovation, Fakulti Teknologi Kejuruteraan Elektrik \& Elektronik (FTKEE), \\ Universiti Teknikal Malaysia Melaka, Malaysia
}

\begin{tabular}{|c|c|}
\hline Article Info & ABSTRACT \\
\hline Article history: & This paper presented an automatic healthcare system where the system able to \\
\hline Received Aug 11, 2018 & $\begin{array}{l}\text { help and facilitates the paralysis patient to complete their daily life. When a } \\
\text { patient suffers from a paralysis attack, the whole or partial of their body maybe }\end{array}$ \\
\hline Revised Nov 20, 2018 & disabled to move which means their movement is restricted and they also \\
\hline Accepted Dec 11, 2018 & barely to communicate with anyone because they are unable to speak like a \\
\hline Keywords: & $\begin{array}{l}\text { to convey and in helping them to manage their daily needs such as eating, } \\
\text { drinking, bathing and etc. By developing this project, the health officer can }\end{array}$ \\
\hline GSM & assist the paralyzed patient when they are alerted by the message from patient \\
\hline Healthcare & via GSM network. There are several instruction of movement gesture sensor \\
\hline Movement gesture & presented in this paper in order to assist health officer in helping the paralyzed \\
\hline Palaysis & $\begin{array}{l}\text { patient to complete their needs. Whenever the patient gives the simple hand } \\
\text { movement instruction, then it will be delivered through SMS and the alerted } \\
\text { notice will be display on notification board to alert the health officers for } \\
\text { assisting the patient. }\end{array}$ \\
\hline
\end{tabular}

Copyright $(2019$ Institute of Advanced Engineering and Science. All rights reserved.

\section{Corresponding Author:}

Siti Asma Che Aziz,

Fakulti Teknologi Kejuruteraan Elektrik \& Elektronik (FTKEE),

Universiti Teknikal Malaysia Melaka, Hang Tuah Jaya,

76100 Durian Tunggal, Melaka, Malaysia.

Email: sitiasma@utem.edu.my

\section{INTRODUCTION}

In advance telecommunication technology, people make it easier and faster to do a something in a long distance with the short time. People always use the technology to complete the work or help a worker to take care of paralyzed patient especially at hospital and also for family who aid paralyzed patient at home or any specific area. Based on the sensor automated wheelchair project [1] it state that, to give assistive in the modern technology is better than before technology world because with the technology can reduce time and facilitate to do daily life.

To relate with problem statement, this project were indicate with utilized automated wheelchair that will help the handicapped or paralyzed person to move by using wheelchair without usage of their hand. The purpose of this project is similar to the paralyzed patient healthcare where both project were invented to help the disabled person in facilitating them in running their daily life easier. Besides that, the automated wheelchair also can be used at hospital and specific area and same goes with paralyzed patient health care that fully used in hospital and still suitable to place the project at specific area such as elderly care center. However, this proposed project only used hand movement to operate by using movement gesture sensor. Even though these projects used main device and sensor, but the purpose of the project invented is same and can solve the problem of paralysis patient in their daily life [2].

Besides that, based on [3] stated that the most problem paralysis disease is their movement is restricted and in every paralyzed patient required almost 24 hours support. This project was invented to help paralyzed patient to control their house without any assistive from another person with only using IR eye Blink sensor 
that consider eye blink as an input. The related purpose of this project with automated paralyzed healthcare system is to provide the patient to operate device without anyone help to do daily life. The similarities with both journal is the basic concept and purpose to aid and help paralysis patient without anyone help. Other than that, the proposed project from [4] that used wireless voice-based wheelchair controller system, which consists of an Android device and a control system that controls the movement of wheelchair using a DC motor. The project aimed to ease the burden for wheelchair user especially for elderly people to move around.

Nowadays, at hospital and NGO's serving paralysis patient is about to take care at their patient almost 24 hours a day. This happened because their patient has a whole or partial body disabled to move by themselves while their also not able to speak properly. This proposed project helps workers or family members who care to the disabled person such as medical staff or doctor to facilitate and treat them.

In this project it is required for the sensor that can afford to fulfil the features within implement this project which is APDS-9960 gesture sensor. This sensor is one of the gesture devices that been used widely around the world such as in the game entertainment which is Wii Controller. Besides that, this project will not used the same device to controller but based on [5], this sensor used to detect the some movement or gesture of human and this sensor aware is the device that consist of five inbuilt sensor depending on internet of sensors. Sense aware will consume low power and gives high performance. It consumes voltage of $3.3 \mathrm{v}$ to $5 \mathrm{v}$.

\section{METHODOLOGY}

This proposed project used the technology in telecommunication, where the evolution in telecommunication was applied in this project by using GSM module SIM900A. At the same time, a few circuit and software such as ARDUINO IDE compiler was used to be as a controller for all of the main and sub equipment. A few main component and equipment are used in this project which is gesture sensor (APDS9960) and controlled by ARDUINO UNO board which act as microcontroller by using GSM module SIM900A.

By using the gesture sensor of (APDS-9960), it will aid the patient to convey anything that they want through the GSM module by sending message. The function of this sensor is the patient just have to swipe their hand at gesture sensor to convey a message. Besides that, the data will be display at the convey sign through LCD screen to easier the patient know what they want to convey. Other than that, the buzzer will sound when there are emergency case occurred if the patient swipe their hand to emergency case. The main concept of entire project is the hand gesture movement act as transmit signal while the gesture sensor will received signal and send data to Arduino board. This concept will help paralyzed patient to convey their instruction or need.

\subsection{Software implementation}

In this part, there are several software were used in this project which is ARDUINO IDE (Integrated Developed Environment) and Proteus 8 Professional. By using the ARDUINO Software (IDE), this software can be written in any programming language to compile and also support the language $\mathrm{C}$ and $\mathrm{C}++$ by using a special rules of code structure. This software will give the ARDUINO UNO board to operate and able to controlled all the process. The ARDUINO UNO board act as the heart of the system and this device is most important and the ARDUINO IDE is required to complete the project. With own program created by this software can controlled any device which connect with ARDUINO board [6].

The software implementation is one of the major components for this project to complete and achieve the planning project as expected. The software also provides the web editor to give opportunity to use and learn this software without downloading. Besides that, before setting up the connection of Arduino board with any devices, the coding need to verify first before uploading the program to the board. The coding will be uploaded into ARDUINO when the compiling process is done without any error. When the coding already burned in ADUINO board, ARDUINO board is able to use and make any connection with any device include GSM module and sensor. Figure 1 shows the connection of ARDUINO Board with PC by using USB cable. The similarities process of GSM is to give notification when the sensor triggered and GSM module will send the short message to owner to take an action [7]. 


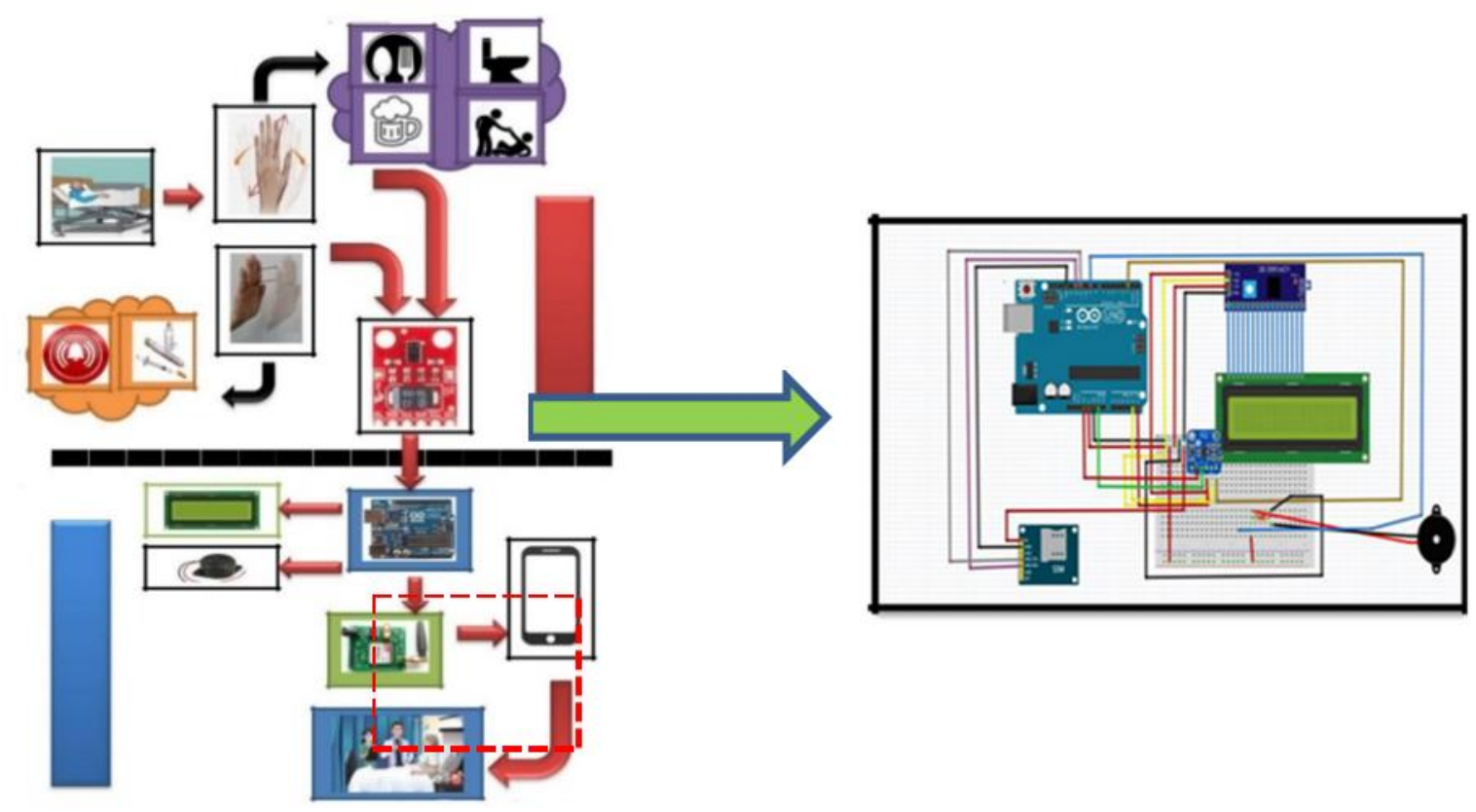

Figure 1. Designed circuit via fritzing software

\subsection{Hardware implementation}

In the circuit implementation will be explain briefly the whole circuit in the project system and also explain about the lock diagram and component to be used in the circuit. Regarding to the project design, the operation of this project is automatic paralysis healthcare system is aid and facilitate the paralysis patient either patient in home or get treatment at Hospital.

Besides, the system of this project also aids the family patient or medical staff to take care of them easier and not 24 hours to treat them. Figure 2 shows the flow chart where the sensor is activated by program code; the sensors will be detected by swiping the hand toward the gesture sensor in particular range. The operation of gesture sensor is detecting any movement with any part of the body mostly by hand which used to convey instruction to help them for example medical staff or nurse at hospital which responsible to treat and care of the patient almost 24 hours every day. There are several hand movement direction set up and each movement direction will indicate different type of instructions for example to help for meals, assist to toilet and etc. So, this system will use to facilitate those care taken of the paralysis patient.

The Arduino is one of the electronic components that use the microcontroller ATmega328 interface where the hardware this board used consist of simple open source hardware board designed around an 8-bit Atmel AVR microcontroller, or a 32-bit Atmel ARM. The GSM Module used in this project is GSM Module SIM 900A due to 2G capabilities in Malaysia was used GSM900 and GSM1800. In this project, GSM Module SIM900A used for sending simple message (SMS) to the consumer after receiving signal from ARDUINO UNO.

The APDS-9960 RGB and gesture sensor is a one of the sensor that combine human and machine interface. This sensor is only requiring the gesture by swiping hand over the sensor. This sensor used to detect some movement or gesture of human and this sensor aware is the device that consists of five inbuilt sensor depending on internet of sensors.

For the gesture sensing example, it has some requirement to make this sensor to function. There are 6 types of gesture will use in this project which is up, down, right, left, near and far. For up, down, left and right are required a distance around 4 to 8 inches $(10$ to $20 \mathrm{~cm})$ above the sensor while for far and near is different way to detect. To detect near gesture part, it will be achieved by holding hand far above the sensor around $25 \mathrm{~cm}$ and then need to bringing hand close to the sensor about $5 \mathrm{~cm}$ over the sensor with hold it at least one second.

For the far gesture part, it will be achieved when hand direct from above close to the sensor about $5 \mathrm{~cm}$ at least one second and need to move by hand up above the sensor. Table 1 below has shown the description and more details of each gesture. 


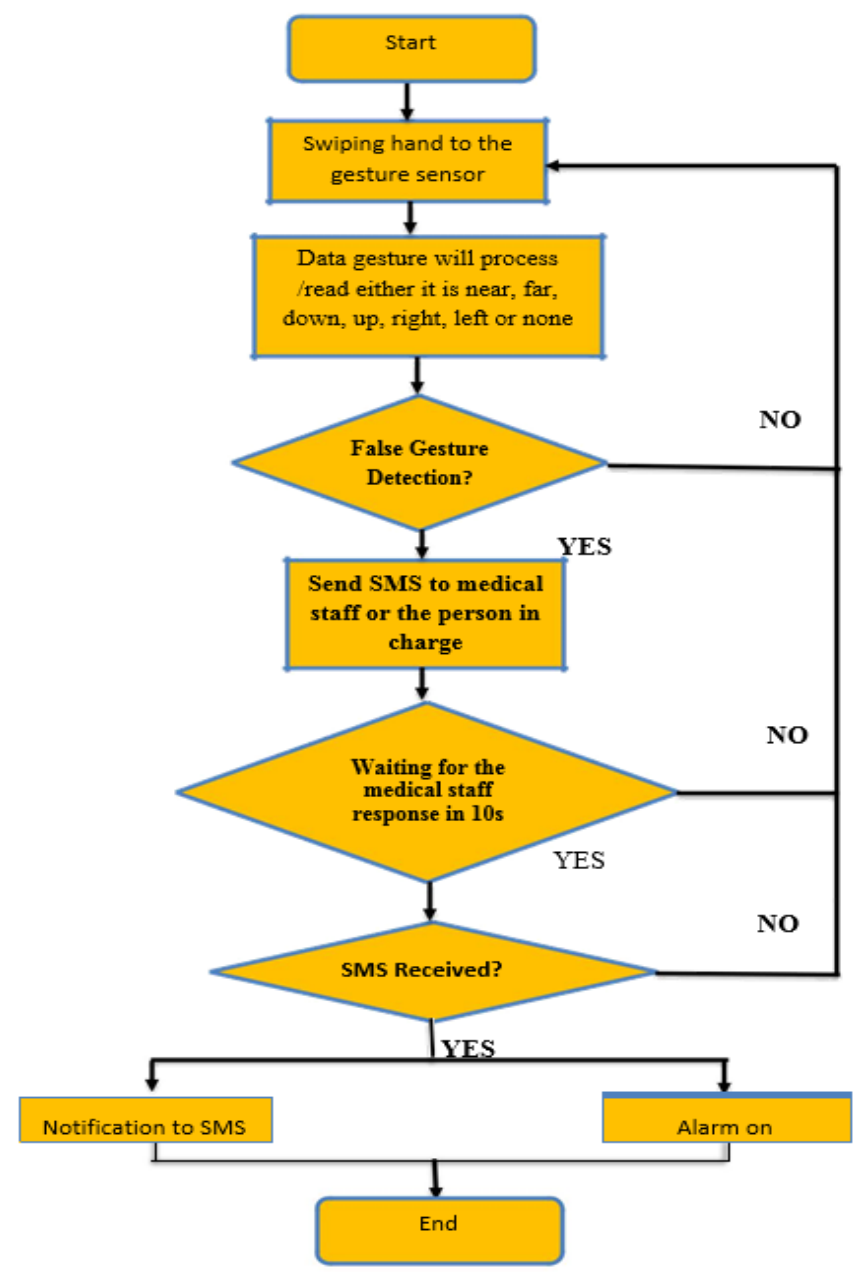

Figure 2. Flowchart of the project system

Table 1. Type of Gesture with Description

\begin{tabular}{|c|c|}
\hline Gesture & Description \\
\hline UP & $\begin{array}{l}\text { A swipe from the bottom of the board to the top and out of range of the sensor. Make sure } \\
\text { that our wrist/arm is not in the sensor's range at the end of the swipe! }\end{array}$ \\
\hline DOWN & A swipe from the top of the board to the bottom and out of range of the sensor. \\
\hline LEFT & A swipe from the right side of the board to the left and out of range of the sensor. \\
\hline RIGHT & A swipe from the left side of the board to the right and out of range of the sensor. \\
\hline NEAR & $\begin{array}{l}\text { Object (e.g. hand) starts far above the sensor, moves close to the sensor, hovers for at least } \\
1 \text { second, and moves out of range of the sensor. }\end{array}$ \\
\hline FAR & $\begin{array}{l}\text { Object starts near the sensor, hovers for at least } 1 \text { second, and then moves up above and } \\
\text { out of range of the sensor. }\end{array}$ \\
\hline NONE & The sensor could not correctly guess the gesture being performed. \\
\hline
\end{tabular}

\section{RESULTS AND DISCUSSION}

The aim of the project was to development of automatic healthcare system using GSM for paralysis patient. The Arduino when Apds-9960 was detected by giving the simple gesture movement. This part was analyzed the time delayed of GSM module and the sensitivity of Apds-9960.

\subsection{Testing of time taken for receiving SMS from GSM to hardware module}

SMS is a text messages for mobile phone sometimes it can takes more time to send or receive a message. It can be happen because of network coverage was weaked at some places. So with this testing, we are able to know how long the duration messages for reach at the other end. This figure below has shown the analysis the performance of the GSM module in this project. Figure 3 shows the block diagram of equipment connection to construct the proposed project respectively. 


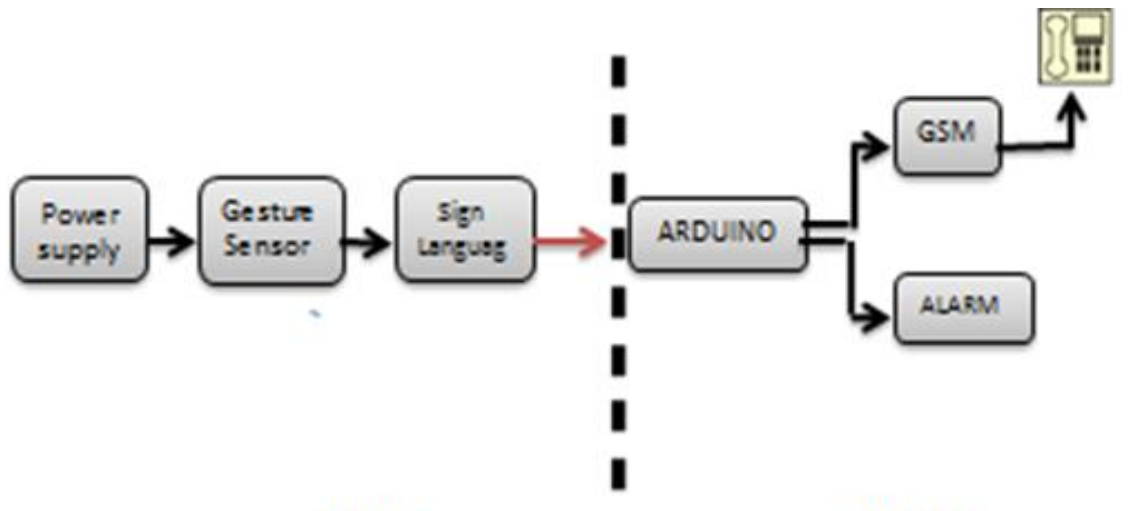

INPUT

OUTPUT

Figure 3. Block diagram of the project system

Time Taken Receive SMS from Gsm VS Numbers of Time Taken Receive Message

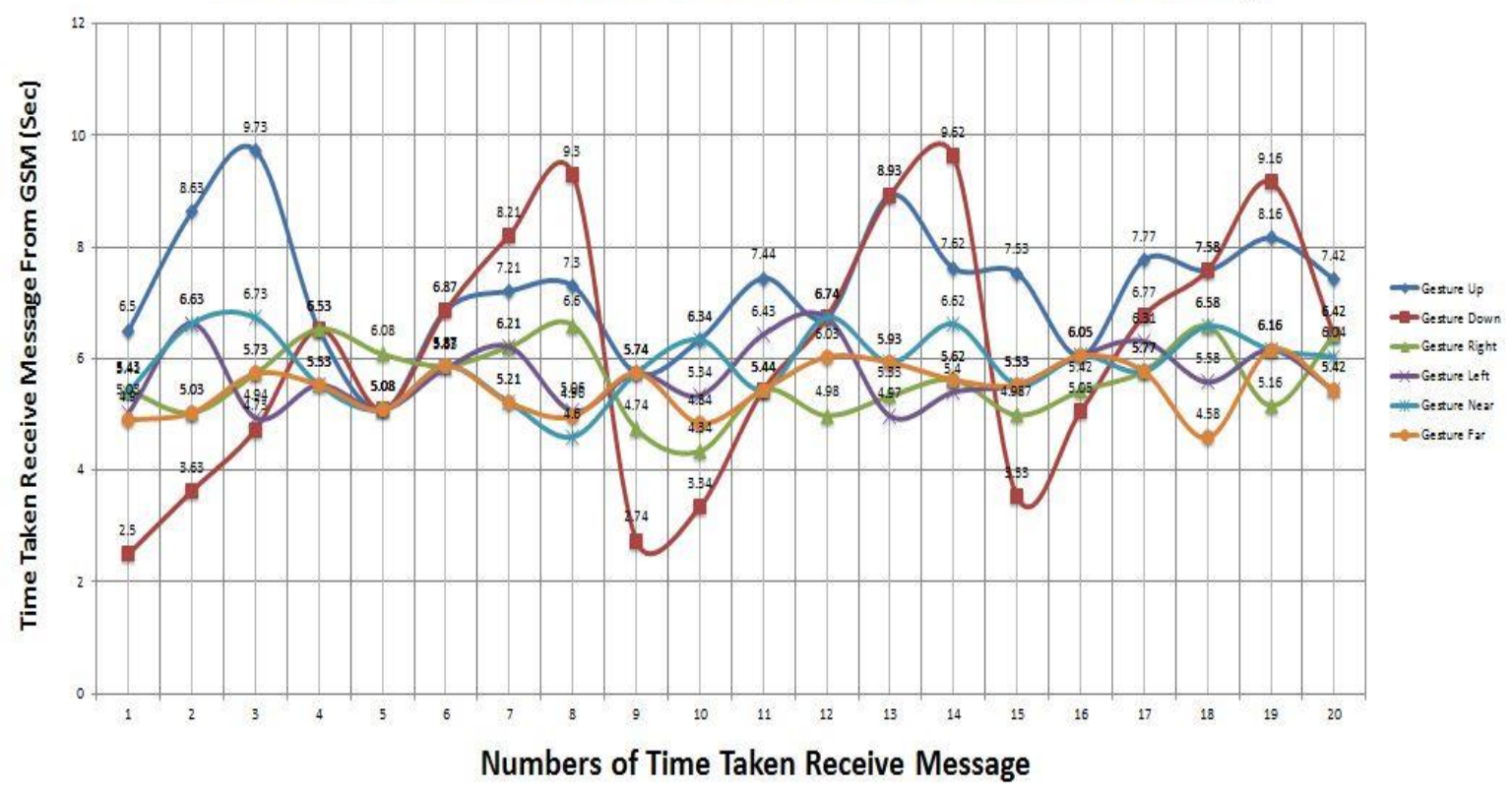

Figure 4. Graph the time taken receive SMS vs. number of time taken receive message

\subsection{Analysis the performance of the system}

Paralysis patient need to take care almost 24 hours and they need someone beside them and care of the. Based on the Figure 5, this system is suitable to use for this project due the sending system is quite faster. Figure 5 shows the efficiency of sensor sensitivity Apds-9960 in this project. From this analysis, this sensor is the most suitable to use due the limitation of this project was achieved.

The features that use in Apds-9960 in this project is gesture detection. The output for this sensor is digital output. There are 4 directional photodiode in this sensor to ensure any gesture movement will convert to digital signal. It occurs from others factor in manufacture of APDS-9960 which is IR LED emission, IR reception and might be environment and the motion. To find out the efficiency and effectiveness APDS-9960 sensor in this project, the gesture detection has been tested to the sensitivity of Apds-9960 sensor was shown in Figure 6. 


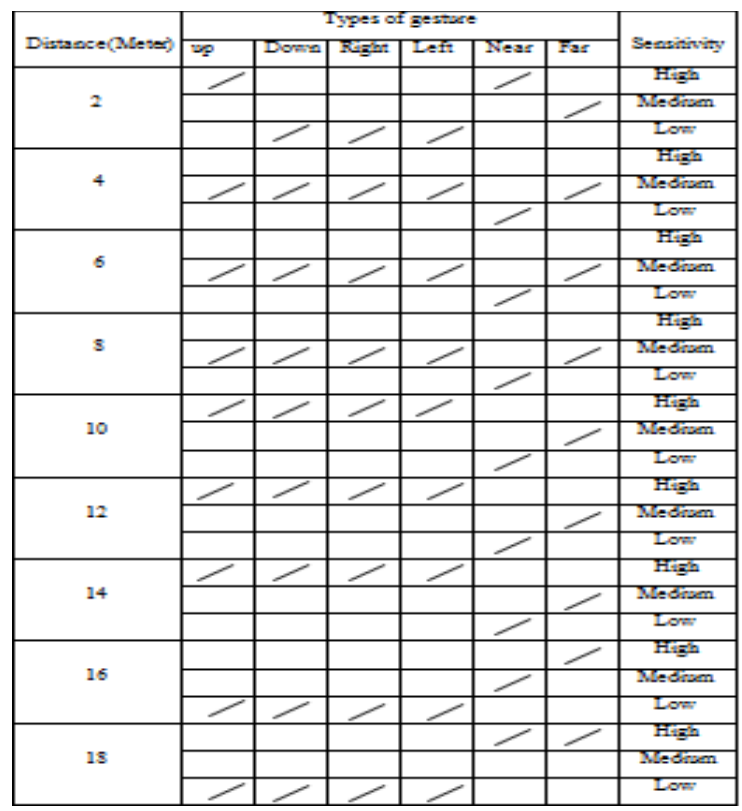

Figure 5. Sensitivity of gesture detection
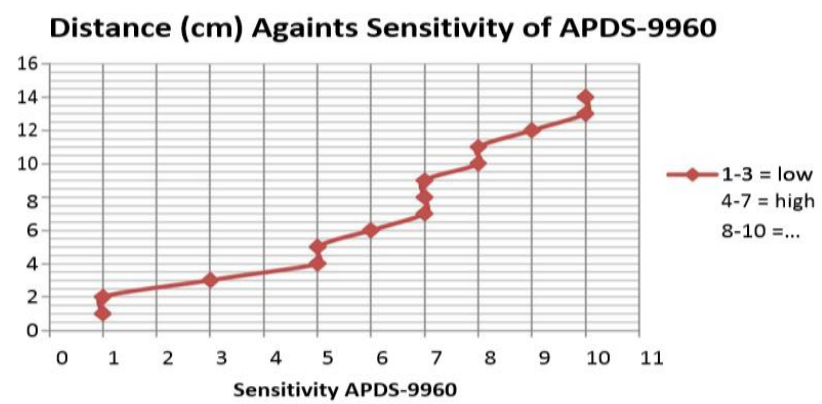

Figure 6. Graph distance against sensitivity of Apds-9960

\section{CONCLUSION AND FUTURE WORK}

As the conclusion, the project was developed to create a system using ARDUINO as the main controller. Aligned with current technologies, this project was created to ensure the paralyze patient obtain the best treatment and care during in hospital without family members to help them just only giving some easy movement gesture to the sensor. Other than that, it also created to analyze the performance of APDS-9960 with GSM module to give attention so that easy to assist their patient before asking what they want. Last but not least, a few improvement still need to be done regarding to the research of automatic healthcare system using GSM system.

To ensure the system still efficient and improve the already system has, a few modification should be made to create the more sophisticated idea for this system. Thus, the automatic Healthcare System using GSM can be upgraded by using several improvement of components, align with the latest technology. A few recommendations can be applied such as upgrading the system at transmission system from GSM Module to the wireless system communication because this system not depending the coverage network from services provider and this system is more sophisticated than GSM system. Use the accelerometer system to ensure that the gesture movement capable read the distance almost 5 meter than this sensor able to read $20 \mathrm{~cm}$ maximum and by using accelerometer able to make sign language via fingers because this system use $\mathrm{x}, \mathrm{y}, \mathrm{z}$ concept. Add the gyroscope system which able to detect if a patient fall down and make this project more useful for patient.

\section{ACKNOWLEDGEMENTS}

This work was supported by Ministry of Education Malaysia with account no. RAGS/1/2015/ICT01/UTEM/03/B00121 and Universiti Teknikal Malaysia Melaka. 


\section{REFERENCES}

[1] C. Vijayakumar, M. P. Kumar, S. Sivaji, S. Sadulla, J. Prathiba and K. V. Kumar, "Sensors based automated wheelchair," International Conference on Green Computing, Communication and Conservation of Energy (ICGCE), Chennai, pp. 439-443, 2013.

[2] Majumdar, M., "The Health Site," Retrieved from Paralysis-Understanding causes, ype, systoms: http://www.thehealthsite.com/diseases-conditions/paralysis-causes-types-symptoms/, 22 May, 2014.

[3] R.K. Moje, Abhijeet Botre, "Sumit pakhare, Vikas Tupe, "Assisting System for Paralyzed," International Journal Of Innovative Research In Electrical, Electronics, Instrumentation And Control Engineering, vol. 4, no. 5, 2016.

[4] Kadmin, A.F., Jidin, A.Z., Bakar, A., Aziz, K.A. and Rashid, W.A., "Wireless Voice-Based Wheelchair Controller System," Journal of Telecommunication, Electronic and Computer Engineering (JTEC), vol. 8, no 7, pp.117-122, 2016.

[5] V. Sirisha,V. Sachin Kumar, "Design and Implementation of Robot Employed with Sense Aware," International Organization of Scientific Research, 2015.

[6] Ismail. S., "Advantages and Disadvantages of Using Arduino," Engineer Experience. Retrieved from http://engineerexperiences.com/advantages-and-disadvatages.html, 2016.

[7] Huzaimy, M., "Wi-Fi and GSM Based Motion Sensor for Home Security System Application," 4th International Conference on Electronic Devices, System and Applications, 2015. 